\title{
RELAÇÕES INTERCULTURAIS EM PROCESSOS EDUCATIVOS DE POVOS RIBEIRINHOS DA AMAZÔNIA ${ }^{1}$
}

\author{
Kleby Miranda Costa ${ }^{2}$ \\ Jorge Domingues Lopes ${ }^{3}$
}

\begin{abstract}
RESUMO
A prática intercultural, no ensino de línguas estrangeiras, colabora para a construção de relações apaziguadoras no campo da tolerância, do respeito ao outro e na recepção de uma leitura positiva da pluralidade social e cultural que vislumbra a vida educacional dos estudantes. O trabalho teve por objetivo analisar as traduções interculturais na pratica de professores de língua estrangeira, da Escola Municipal de Ensino Fundamental Almirante Barroso, na cidade de Mocajuba PA, destacando neste processo a tradução cultural e a dimensão linguística, na escola ribeirinha. Durante esta jornada investigativa, o referido projeto apresentou contribuições teóricas que ajudaram a formar uma nova visão nestes entre lugares de interação linguística e cultural: Jorge Larrosa (2002); Jacques Derrida (2002) em uma visão pós-colonial destacou-se: Homi Bhabha (2011) e com uma abordagem póscrítica no campo do currículo: Sandra Corazza (2007); Michael Foucalt (2013) e Tomaz Tadeu da Silva (2000). Os resultados apontaram que os elementos linguísticos estão diretamente ligados com as questões culturais tanto do idioma sendo estudado, quanto da própria cultura local. Essa ligação se dá através de um diálogo entre identidade e diferença. O presente estudo percutiu na criação de um projeto social no ano de 2014 que teve parceria com universidades públicas da região, onde proporcionou aulas de língua inglesa gratuitas, para diversos jovens de escolas públicas do município de Mocajuba PA.
\end{abstract}

Palavras-chave: Interculturalidade. Língua inglesa. Escola ribeirinha.

\begin{abstract}
Intercultural practice, in the teaching of foreign languages, contributes to the construction of soothing relationships in the field of tolerance, respect for others and the reception of a positive reading of the social and cultural plurality that envisions the educational life of students. The objective of this work was to analyze the intercultural translations in the practice of foreign language teachers, at the Almirante Barroso Elementary School, in the city of Mocajuba PA, highlighting in this process the cultural translation and the linguistic dimension in the riverside school. During this investigative

\footnotetext{
${ }^{1}$ O presente trabalho tem relação com a pesquisa desenvolvida no programa de Pós-graduação em Educação e cultura, no curso de mestrado Acadêmico, pela Universidade Federal do Pará, onde está sendo orientado pelo professor doutor Jorge Domingues Lopes. O presente artigo está sendo submetido a nova revista amazônica a convite do seminário internacional de linguagens, saberes e sociodiversidade na Amazônia, para publicação em edição especial.

${ }^{2}$ Mestrando em Educação e Cultura pela Universidade Federal do Pará. Linha de pesquisa: Educação, Cultura e Linguagem. Especialista em Ensino e Aprendizagem de Língua Inglesa e suas Literaturas pela UFPA. Professor Colaborador da Universidade Federal do Pará, Campus Universitário do Tocantins/Cametá. Membro colaborador/voluntário do grupo de pesquisa PHILIA: Filosofia, Linguagem e Alteridade na Educação (UFPACametá), coordenado pela professora Doutora Gilcilene Dias da Costa e Compõe o grupo de pesquisa documentação e análise de línguas indígenas e não indígenas amazônicas e sua interface com a cultura e a educação; coordenado pelo professor doutor Jorge Domingues Lopes. E-mail: klebycosta@yahoo.com.br

${ }^{3}$ Orientador do Mestrando Kleby Miranda Costa, no PPGEDUC. Doutor em Linguística pelo Programa de PósGraduação em Linguística da Universidade de Brasília (UnB). Mestre em Letras pela Universidade Federal do Pará (UFPA) e graduado em Licenciatura Plenas em Letras com habilitações em Língua Portuguesa e Língua Francesa pela UFPA. Atualmente é professor adjunto da UFPA, lotado no Campus Universitário do Tocantins/Cametá. Professor permanente do Programa de Pós-Graduação em Educação e Cultura (PPGEDUC/UFPA), professor colaborador da Pós-Graduação em Educação Escolar Indígena (PPGEEI/UEPAUFPA-UFOPA-UNIFESSPA).
} 
journey, this project presented theoretical contributions that helped to form a new vision in these between places of linguistic and cultural interaction: Jorge Larrosa (2002); Jacques Derrida (2002) in a postcolonial view stood out: Homi Bhabha (2011) and with a post-critical approach in the field of curriculum: Sandra Corazza (2007); Michael Foucalt (2013) and Tomaz Tadeu da Silva (2000). The results pointed out that the linguistic elements are directly linked with the cultural questions of the language being studied, as well as of the local culture itself. This connection occurs through a dialogue between identity and difference. This study aimed at creating a social project in 2014 that partnered with public universities in the region, where it provided free English language classes to several young people from public schools in the city of Mocajuba PA.

Keywords: Interculturality. English language. Riverside school.

\section{FIOS DE MEMÓRIAS NA AMAZÔNIA}

A prática intercultural, no ensino de línguas estrangeiras, proporciona a construção de relações apaziguadoras no campo da tolerância, do respeito ao outro e na recepção de uma leitura positiva da pluralidade social e cultural que vislumbra a vida educacional dos estudantes.

Ao exercitar a interculturalidade, em sala de aula e principalmente na formação de professores de línguas, o professor formador articula uma proposta de alteridade na educação. (FLEURI, 2003). Em outras palavras, "propostas que visam promover a relação e o respeito entre grupos socioculturais, mediante processos democráticos e dialógicos" (FLEURI, 2003, p. 17).

Diante de tais premissas, o presente trabalho teve por objetivo analisar as traduções interculturais na prática de professores de língua estrangeira, da Escola Municipal de Ensino Fundamental Almirante Barroso, na cidade de Mocajuba PA, destacando neste processo a tradução cultural e a dimensão linguística, na escola ribeirinha.

"De acordo com os estudos culturais a identidade é relacional, ou seja, ela é um sistema de significação" que se constrói perante as diferentes relações sociais entre indivíduos em sociedade. (COSTA; LOUZADA e SANTOS, 2019, p. 242).

Diante disso, Hall (2011) enfatiza que "aquelas pessoas que sustentam que as identidades modernas estão sendo fragmentadas" em outras palavras, considerando as concepções de sujeitos mencionadas por Hall (2011), "argumentam que o que aconteceu à concepção do sujeito moderno, na modernidade tardia, não foi simplesmente sua desagregação, mas seu deslocamento.” Então "elas descrevem esse deslocamento através de uma série de rupturas nos discursos do conhecimento moderno" (HALL, 2011, p. 34).

Para denominar esta identidade, passamos por dificuldades que Spink (2011) ressalta: 
Temos certa dificuldade de nomear esse ser que somos quando teorizamos a respeito da vida em sociedade e, nesse âmbito, nem sempre tomamos alguns cuidados no uso de nossas categorias. Por exemplo, incorporando o gênero de fala próprio aos manuais de metodologia, falamos de sujeitos, quando nos referimos aos "participantes" de nossas pesquisas. Por suas conotações "ideológicas", procuramos evitar o uso da palavra indivíduo, mas a deixamos escapar em seus múltiplos sentidos: individualmente, para nos referirmos a cada um de um grupo; individualismo para nos reportarmos a modos de vida pouco solidários. (SPINK, 2011, p. 1).

Considerando a interação entre professores e estudantes, no que tange as trocas de negociações discursivas no contexto educacional, neste caso o ambiente mocajubense, podemos, de maneira sucinta, afirmar que cada discurso produzido, nestes espaços de interação, possui um componente ou melhor "um sistema de transitividade que é inteiramente relacionado com a formação dos planos no discurso" (NEVES, 1997, p. 26).

Diante de tais considerações, a pesquisa contornou e adentrou ao campo da tradução cultural, levantando questões de identidade e diferença, acerca dos sentidos produzidos, nas trilhas do conhecimento. Cada tradução cultural, compartilhada e construída no lócus ribeirinho observado pela pesquisa, demonstrou uma grande interação entre a cultura estrangeira e local.

"A subjacente interação cultural no espaço ribeirinho", que é objeto de estudo "teve como ponto de convergência" os espaços culturais utilizados na prática docente, "por dois professores da disciplina de língua inglesa. Assim, a pesquisa focou em apresentar uma visão de sala de aula e seus entre- lugares como lócus de investigação" (COSTA, 2018, p. 2).

Seguindo esta abordagem, definir linguagem, cultura e tradução em um contexto cultural ribeirinho, torna-se uma tarefa rica, complexa e fascinante. Diante dos encontros reflexivos que foram norteados de maneira preliminar e que proporcionaram uma extensa reflexão no autor deste trabalho, diversas perguntas foram levantadas e nelas problemas e questionamentos foram construídos.

Em 2013 foi desenvolvida uma pesquisa qualitativa, baseando-se na construção e realização de entrevistas semiestruturadas, com docentes da Escola Almirante Barroso, na cidade de Mocajuba PA. Nesta pesquisa, foram questionadas e problematizadas as (im) possibilidades da tradução e do ensino de língua inglesa, em uma perspectiva intercultural, considerando o cruzamento da cultura estrangeira e ribeirinha.

O presente estudo percutiu na criação de um projeto social, no ano de 2014, que teve parceria com universidades públicas da região, onde proporcionou aulas de língua inglesa, gratuitas, para diversos jovens de escolas públicas do município de Mocajuba PA. 
Ao refletir sobre os sujeitos que integram a escola básica ribeirinha e sua interação e influência nesta jornada ou melhor neste palco da vida educacional, social, cultural e principalmente ideológica dos educandos, concebemos as vozes, que se manifestam nestes entre lugares, de forma heterogênea. Desta maneira, a pesquisa foi conduzida em uma visão interativa entre os sujeitos que se constroem perante as trocas sociais (COSTA, 2018).

\footnotetext{
Tomando como base a concepção de que as vozes da Amazônia, ou seja, cada sujeito se constrói na relação com o outro e com a linguagem, os discursos dos sujeitos-professores de língua inglesa foram sendo tecidos e conduzidos como uma passagem do conhecimento científico para o conteúdo curricular em sala de aula e tidos como pilar investigativo deste trabalho (COSTA, 2018, p. 3).
}

As explanações sobre a figura docente, escola e principalmente as vozes que se articulam com os sujeitos da educação, estiveram envolvidas e explícitas, também, nos meandros deste estudo, juntamente com os saberes e experiências de cada falante que compõe o currículo educacional ribeirinho.

Durante esta jornada investigativa, o referido projeto apresentou contribuições teóricas que ajudaram a formar uma nova visão nestes entre lugares de interação linguística e cultural: Jorge Larrosa (2002); Jacques Derrida (2002) em uma visão pós-colonial destacou-se: Homi Bhabha (2011) e com uma abordagem pós-crítica no campo do currículo: Sandra Corazza (2007); Michael Foucault (2013) e Tomaz Tadeu da Silva (2000). Os resultados apontaram que os elementos linguísticos estão diretamente ligados com as questões culturais tanto do idioma sendo estudado, quanto da própria cultura local. Essa ligação se dá através de um diálogo entre identidade e diferença (COSTA, 2018).

\section{DESLOCAMENTOS CULTURAIS NA AMAZÔNIA TOCANTINA}

A cidade de Mocajuba é o menor município, em dimensões geográficas, do baixo Tocantins. Porém, suas inúmeras riquezas naturais e, sobretudo, o cultivo da pimenta do reino proporcionaram o crescimento do município. Mocajuba contém uma grande diversidade espacial, com suas praias e sua diversidade, em fauna e flora. Para os moradores locais, a cidade é vista como tipicamente ribeirinha. Sua disposição geográfica permite, ao visitante, contemplar um divino pôr do sol, além de conhecer a interação, dos moradores locais, com os botos, que vêm sendo estudada, por biólogos da Universidade Federal do Pará. 
Figura 1: Interação dos pesquisadores da UFPA com os botos de Mocajuba PA

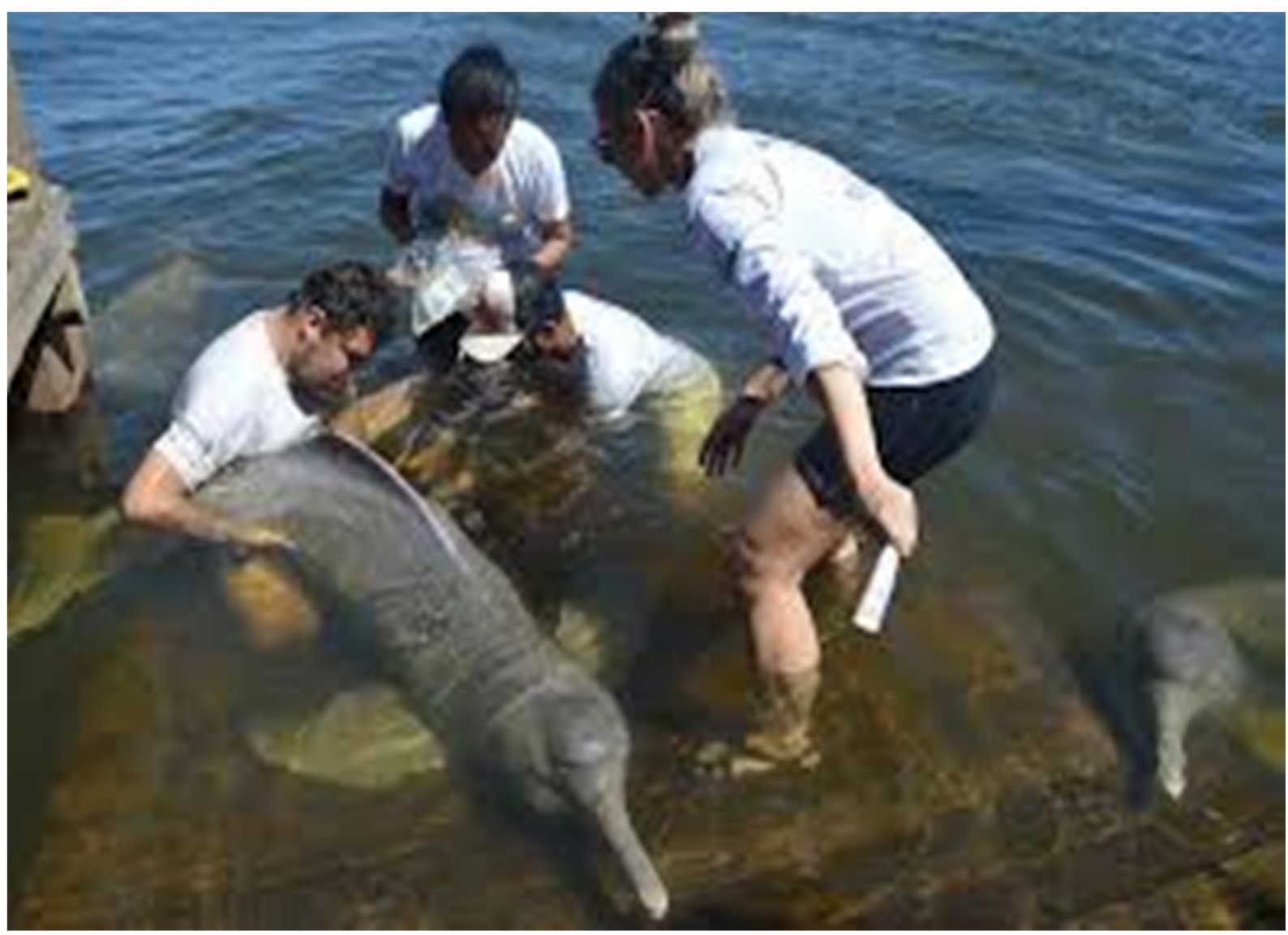

Fonte: grupo de pesquisa BioMA/ UFPA

Nesse sentido, compreender a constituição da identidade do sujeito ribeirinho, na organização social dentro do espaço Mocajubense, requer uma reflexão sobre diferentes formas de convívio social, distribuídas nos trâmites do cotidiano de homens e mulheres mocajubenses. Assim, para compreender esta reflexão, recorrei a Clastres (1978), ao afirmar:

Podemos então medir o valor e o alcance da oposição sócio-econômica [sic] entre homens e mulheres porque ela estrutura o tempo e o espaço dos guaiaqui. Ora eles não deixam no impensado o vivido dessa- praxis: têm uma. Consciência clara e o desequilíbrio das relações económicas entre os caçadores e suas esposas se exprime, no pensamento dos índios, como a oposição entre o arco e o- cesto. Cada um desses dois instrumentos é, com efeito, o meio, o signo e o resumo de dois "estilos" de existência tanto opostos como cuidadosamente separados, Quase não é necessário sublinhar que o arco, arma única dos caçadores, é um instrumento exclusivamente masculino e que o cesto, coisa, das mulheres, só é utilizado por elas: os homens caçam, as mulheres carregam. A pedagogia dos guaiaqui se estabelece principalmente nessa grande divisão de papéis. Logo aos quatro, ou cinco anos, o menino recebe do pai, um pequeno arco adaptado ao seu tamanho; a partir de então ele começará a se exercitar na arte de lançar com perfeição uma flecha. (CLASTRES, 1978, p. 74). 
Segundo Todorov (1996) "Diante desta compreensão cultural, até mesmo etnografada nos escritos de Colombo, apreende-se que o sujeito se constitui em interação com o meio social em que vive" (COSTA; LOUZADA e SANTOS, 2019, p. 251).

"Compreendemos os deslocamentos identitários, de diferentes povos, com suas diferentes culturas. Muitas delas usurpadas de maneira voraz pelo colonizador" (COSTA; LOUZADA e SANTOS, 2019, p. 251). "O lado humano dos espanhóis é a sede que têm de bens terrestres: o ouro, como vimos, desde o início, e, em seguida, as mulheres" (TODOROV, 1996, p. 40).

“Assim, compreende-se que a identidade cultural é uma teia de infinitas relações sociais, estabelecidas historicamente, tecendo valores entre os indivíduos de uma sociedade. Então, a partir dos estudos culturais pode-se criar novas possibilidades de compreender a interação do sujeito com a sociedade e principalmente a constituição de sua identidade" (COSTA; LOUZADA e SANTOS, 2019, p. 251-252).

Seguindo este embasamento e "refletindo sobre as enunciações que são construídas e desconstruídas diariamente na vivência docente ribeirinha" (COSTA, 2018, p. 3), concebi a "formação de professores" não como um ato meramente isolado, mas como uma construção de experiências ligadas ao existir em sala de aula e nas trocas de negociações (LARROSA, 2000). Bhabha "proporciona uma reflexão sobre o fato de cada indivíduo entrar em interação com o outro, na busca por uma "identidade". Em referência, ao projeto, podemos determina-la como: identidade de professores" de inglês (COSTA, 2018, p. 3).

[...] não são correlacionados por partilharem da mesma causa histórica ou por serem mediados pelo mesmo signo. A sua relação é performativa, uma relação com o acontecimento que muda através do exercício da sua enunciação e da sua interpretação [...] (BHABHA, 2011, p. 128).

A enunciação é o ato de utilização da língua pelo falante em diferentes contextos discursivos, neste caso específico falarei do ambiente escolar ribeirinho. Dentro deste contexto os discursos produzidos não são considerados como meras individualidades, mas como lócus enunciativos do entre lugar. (FOUCAULT, 2013).

Ricoeur (2011) "amplifica este debate entorno do campo discursivo e na capacidade de reflexão da língua. $\mathrm{O}$ autor discorre sobre a possibilidade da tradução não se restringir em apenas uma transferência de significados" (COSTA, 2018, p. 5).

[...] não são frases ou palavras, mas textos que nossos textos querem traduzir. E os textos, por sua vez, fazem parte de conjuntos culturais através dos quais se exprimem visões de mundo diferentes, que aliás, podem se afrontar no interior do 
mesmo sistema elementar de recorte fonológico, lexical, sintático, a ponto de fazer do que chamamos cultura nacional ou comunitária uma rede de visões do mundo em competição oculta ou aberta [...] (RICOUER, 2011, p. 60 -61).

Derrida (2002, p. 27) ressalta que a tarefa do tradutor é uma “[...] missão à qual se está (sempre pelo outro) destinado; o engajamento, o dever, a dívida, a responsabilidade." Assim como para Costa $(2018$, p. 6) "a identidade cultural é marcada pela diferença e para compreender o que torna este conceito central, Silva (2000) apresenta os diferentes níveis de identidade".

[...] para compreender o que faz da identidade um conceito tão central, precisamos examinar as preocupações contemporâneas com questões de identidade em diferentes níveis. $\mathrm{Na}$ arena global, por exemplo, existem preocupações com as identidades nacionais e com as identidades étnicas; em um contexto mais "local", existem preocupações com a identidade pessoal [...] (SILVA, p. 10, 2000).

“As significações produzem relação de poder e nesta conexão surge a definição dos excluídos ou dos que se encaixam no sistema" (COSTA, 2018, p. 6). "A cultura molda a identidade ao dar sentido à experiência e ao tornar possível optar, entre as várias identidades possíveis, por um modo específico de subjetividade” (SILVA, p. 12, 2000).

"Ao realizar este processo de reflexão entorno da cultura e sua relação com a linguagem, tomamos uma nova visão de sujeito que passa a interagir nestes encontros enunciativos". Desta maneira, Eco (2007), "ressalta que a tradução vai muito além de uma simples transferência de significados" (COSTA, 2018, p. 6), pois "Já foi dito, e trata-se hoje em dia de ideia aceita, que uma tradução não diz respeito apenas a uma passagem entre duas línguas, mas entre duas culturas" [...] (ECO, 2007, p. 190).

"Perante esta heterogeneidade de discursos que a pesquisa apresentou as comunidades da Amazônia Tocantina e aos leitores. Corazza (2007) propõe um processo linear na construção desta escrita" (COSTA, 2018, p. 6).

[...] sempre costuma chegar um tempo em que é preciso descrever como realizamos as práticas de investigação. Este tempo não é o do relógio, nem aquele de tipo cronológico; não advém de nenhuma herança metafísica; não é determinado por qualquer ordenação causal; assim como não integra algum etapismo evolucionista, por onde irrecorrivelmente devamos passar para atingir um estágio de maior progresso. Ao contrário, para que este tempo se constitua - na descontinuidade que lhe é própria -, é preciso que necessidades específicas tenham sido criadas tais como nossas atividades (CORAZZA, 2007, p. 103 -107). 
Esta pesquisa proporcionou, também, um estudo mais avançado no que tange o âmbito do mestrado acadêmico. Nele aprofundarei meus conhecimentos e poderei investigar a fundo estes conceitos, problemas, questões e teorias.

\section{A PERSPECTIVA DA EDUCAÇÃO MULTICULTURAL CRÍTICA E EMANCIPATÓRIA NA AMAZÔNIA}

Antes de adentrar, aos caminhos formadores da prática docente em língua estrangeira, é necessário entender que o termo "multicultural" tem sido proclamado como unidade descritiva, em momentos analítica, ora sociológica e por fim histórica. O que indica diferentes relações sociais e diferentes grupos sociais convivendo em um mesmo ambiente social. (FLEURI, 2003).

Segundo Fleuri (2003, p. 17) o "adjetivo intercultural tem sido utilizado para indicar realidades e perspectivas incongruentes entre si (...) há quem amplia o conceito de interculturalidade de modo a compreender o "diferente" (...)". O autor completa dizendo que "há ainda quem considera interculturalidade como sinônimo de "mestiçagem".

Diante disso o campo da formação de professores contempla a incompletude do ser humano, no que implica as diferentes relações sociais e sua formação permanente. Sobre a ótica freireana, formação e prática pedagógica estabelecem uma relação contínua, ou seja, se constituindo através de seu olhar reflexivo sobre a prática. (FREIRE, 1997).

Paulo Freire (1997) contribuiu e contribui de maneira significativa no processo de formação de professores para a educação básica. Seu olhar dialógico promulgou concepções de mundo e cultura que definiram o lugar dos professores e alunos no ambiente educacional. Tal perspectiva conduziu, as teorias e conceitos, a constituição de um modelo crítico e criativo, da relação professor e aluno.

Sobre a égide educativa, diferentes docentes lecionam em palcos educacionais distintos e esse fazer pedagógico se manifesta sobretudo no ambiente educacional elegendo-o como lócus docente. Freire (2009, p. 90-91) ressalta que "A palavra verdadeira, que é trabalho, que é práxis, é transformar o mundo, dizer a palavra não é privilégio de alguns homens [e mulheres], mas direito de todos os homens [mulheres]."

Diante do pensamento do autor, remetemos nossa compreensão na palavra como instrumento de compreensão da realidade social, histórica e cultural. É através do discurso que é objetivada a interação entre professor e estudante no contexto educacional. E essa 
interação visa humanizar os sujeitos aprendizes a priori e a posteriori de seu exercício da cidadania.

No exercício da docência é comum presenciarmos, na educação básica, elementos tradicionais que promovem ou que são transmissores de conteúdo. Desta maneira, muitos docentes, adeptos desta pedagogia tradicional, possuem uma crença voltada na "disciplina curricular" como sendo a única detentora ou o único instrumento utilizável para uma prática pedagógica eficiente.

Esta visão reducionista do trabalho docente aprofunda reflexões sobre a importância da criticidade como elemento indispensável na formação de professores. Desta maneira, a criticidade, é elemento fundamental para o desenvolvimento de práticas pedagógicas humanizadoras.

Segundo Libâneo (2011, p. 88) "o professor atua como mediador da relação cognitiva do aluno com a matéria. (...) em outras palavras, o ensino satisfatório é aquele em que o professor põe em prática e dirige as condições e os modos que asseguram um processo de conhecimento pelo aluno".

Desta maneira o autor concebe o papel do professor como um mediador, contribuindo para com o desenvolvimento do estudante, direcionando o discente para uma apropriação adequada do conhecimento. Desta maneira, o trabalho docente consiste na valorização de conteúdos que consistam no desenvolvimento de capacidades intelectuais dos educandos. (LIBÂNEO, 2011, p. 88).

As relações educacionais, no bojo de sua problemática, se esfacelam em diferentes dimensões no âmbito da educação básica. Tais dimensões, segundo Candau e Moreira (2008, p. 13) “discorrem sobre uma universalização da escolarização, qualidade da educação, projetos político pedagógicos, dinâmica interna das escolas, concepções curriculares, relações com a comunidade, função social da escola, indisciplina e violência escolares”.

Essas relações apontadas pelos autores, também, se associam com as dimensões “do processo de avaliação no plano institucional e nacional, formação de professores/ as, entre outras.” (CANDAU; MOREIRA 2008, p. 13). Segundo Candau e Moreira (2008) não é possível compreender um trabalho pedagógico, ou seja, o fazer docente nas trilhas da experiência, de maneira, desconectado da cultura, em outras palavras deverá haver uma íntima relação entre educação e cultura nos alicerces das instituições educacionais.

A luta pela heterogeneidade cultural das escolas vem ganhando adeptos nos últimos anos, entretanto a prática padronizadora, homogeneizadora e mono cultural da educação está cada vez mais presente na vivência de nossos jovens da Amazônia. 
A escola é um espaço de cruzamento de culturas, (CANDAU; MOREIRA, 2008), um ambiente onde as instâncias da socialização estão intimamente ligadas não apenas com as identidades juvenis, como também estão mediadas por uma reflexão da pluralidade cultural presente em diversas instituições no baixo Tocantins. Candau e Moreira (2008, p. 19) enfatiza que:

Outra dificuldade para se penetrar na problemática do multiculturalismo está referida à polissemia do termo. A necessidade de adjetivá-lo evidencia esta realidade. Expressões como multiculturalismo conservador, liberal, celebratório, crítico, emancipador, revolucionário podem ser encontradas na produção sobre o tema e se multiplicam continuamente. Certamente inúmeras e diversificadas são as concepções e vertentes multiculturais.

Desta forma, os autores creem na importância imprescindível da descrição terminológica da palavra "multiculturalismo", como "uma maneira de atuar, de intervir, de transformar a dinâmica social.” (CANDAU; MOREIRA, 2008, p. 20). Os autores salientam que não existe igualdade de oportunidade para todos.

"Há grupos, como os indígenas, negros, homossexuais, pessoas oriundas de determinadas regiões geográficas (...).” E, também, “com baixos níveis de escolarização, com deficiência que não tem os mesmos acessos a determinados serviços. (CANDAU; MOREIRA, 2008, p. 20).

Dentro de uma perspectiva intercultural da educação divergentes características manifestam seu entender. "Uma primeira (...) é a promoção deliberada da inter-relação entre diferentes grupos culturais presentes em uma determinada sociedade. (CANDAU; MOREIRA, 2008, p. 22). Assim, o processo de afirmação de uma identidade cultural sofre favorecimentos desiguais, causando assim o choque entre diferentes culturas.

Contudo, Caudau e Moreira (2008, p. 22), “concebe as culturas em contínuo processo de elaboração, de construção e de reconstrução. Certamente cada cultura tem suas raízes, mas estas são históricas e dinâmicas." A terceira característica apontada pelos autores discorre sobre o processo de hibridização das culturas. Segundo os autores estes processos são:

\footnotetext{
Intensos e mobilizadores da construção de identidades abertas, em construção permanente, o que supõe que as culturas não são "puras". A hibridização cultural é um elemento importante para se levar em consideração na dinâmica dos diferentes grupos socioculturais. A consciência dos mecanismos de poder que permeiam as relações culturais constitui outra característica desta perspectiva. (CANDAU: MOREIRA, 2008, p. 22- 23).
}

As relações culturais são construídas na história e estão associadas com as relações de poder, ou seja, relações hierarquizadas, enraizadas pelo preconceito e discriminação de 
variados grupos (CANDAU; MOREIRA, 2008). "Uma última característica (...) diz respeito ao fato de não desvincular as questões da diferença e da desigualdade presentes hoje de modo particularmente conflitivo." (CANDAU; MOREIRA, 2008, p. 23). Estas diversas configurações, imersas no plano mundial e social, ajustam suas estruturas sem valer-se do reducionismo cultural.

Os autores defendem uma perspectiva intercultural visando uma educação pautada no reconhecimento do outro, "para o diálogo entre os diferentes grupos sociais e culturais. Uma educação para a negociação cultural, que enfrenta os conflitos provocados pela assimetria (...)", em outras palavras uma alteridade "de poder entre os diferentes grupos socioculturais nas nossas sociedades e é capaz de favorecer a construção de um projeto comum, pelo qual as diferenças sejam dialeticamente incluídas." (CANDAU; MOREIRA, 2008, p. 23).

As diferenças enraizadas no chão das escolas, visto que a cultura é marcada pela homogeneização e por um caráter mono cultural. Partindo do princípio de valorização e ressignificação didática entendemos a necessária caminhada pedagógica como elemento crucial no reconhecimento das identidades culturais. Segundo Candau e Moreira (2008, p. 26):

\begin{abstract}
Tendemos a uma visão homogeneizadora e estereotipada de nós mesmos, em que nossa identidade cultural é muitas vezes vista como um dado "natural". Desvelar esta realidade e favorecer uma visão dinâmica, contextualizada e plural das nossas identidades culturais é fundamental, articulando-se a dimensão pessoal e coletiva destes processos. Ser conscientes de nossos enraizamentos culturais, dos processos de hibridização e de negação e silenciamento de determinados pertencimentos culturais, sendo capazes de reconhece-los, nomeá-los e trabalhá-los constitui um exercício fundamental.
\end{abstract}

A socialização das identidades culturais entre os jovens configura-se como uma bricolagem de emoções ligadas ao processo de formação identitária do alunado. Todavia, Geertz (2008, p. 4) defende o conceito de cultura demonstrando ser "essencialmente semiótico. Acreditando, como Max Weber, que o homem é um animal amarrado a teias de significados que ele mesmo teceu".

Assim, o autor discorre que a cultura é uma teia e sua análise, como uma ciência interpretativa, está à procura de significado. A cultura é um patrimônio imaterial público. $\mathrm{O}$ estudo da cultura com uma concepção científica significativa.

"A perspectiva iluminista do homem era, naturalmente a de que ele constituía uma só peça com a natureza e partilhava da uniformidade geral de composição" sendo assim, afirmamos "que a ciência natural havia descoberto sob o incitamento de Bacon e a orientação de Newton.” Em outras palavras “(...) há uma natureza humana tão regularmente organizada, 
tão perfeitamente invariante e tão maravilhosamente simples como o universo de Newton." (GEERTZ, 2008, p. 25). Ainda segundo o autor,

\begin{abstract}
A enorme e ampla variedade de diferenças entre os homens, em crenças e valores, em costumes e instituições, tanto no tempo como de lugar para lugar, é essencialmente sem significado ao definir sua natureza. Consiste em meros acréscimos, até mesmo distorções, sobrepondo e obscurecendo o que é verdadeiramente humano - o constante, o geral, o universal - no homem. (GEERTZ, 2008, 26).
\end{abstract}

Através dessas interpretações a antropologia tenta encontrar uma definição de homem onde a cultura e a variabilidade cultural possam ser entendidas sem preconceito e sem expressões vazias. "Alimentar a ideia de que a diversidade de costumes no tempo e no espaço não é simplesmente uma questão de indumentária ou aparência (...) humanidade é tão variada em sua essência como em sua expressão.” (GEERTZ, 2008, p. 27).

\title{
CONSIDERAÇÕES FINAIS
}

Diante das trilhas discursivas que emergem no ambiente educacional ribeirinho da cidade de Mocajuba, contemplei saberes que, atrelados aos aspectos linguísticos do inglês, como disciplina da educação básica, despertaram uma euforia, no ato de pesquisar, que instigou o desenvolvimento deste trabalho. Nos trâmites linguísticos da cultura e da tradução, da literatura local, do folclore e das lendas; da cobra grande, da Maria da pedra, do boto e da Matinta Pereira, foram entrando em contato com uma outra cultura, a saber: a da língua inglesa.

As lendas são frutos da tradição popular, em outras palavras uma narrativa transmitida oralmente por indivíduos visando explicar acontecimentos misteriosos ou sobrenaturais. Nas lendas, são misturados fatos reais com imaginários ou fantasias que vão se modificando conforme sua reprodução pelos habitantes de determinada comunidade. 
Figura 2: Cobra grande

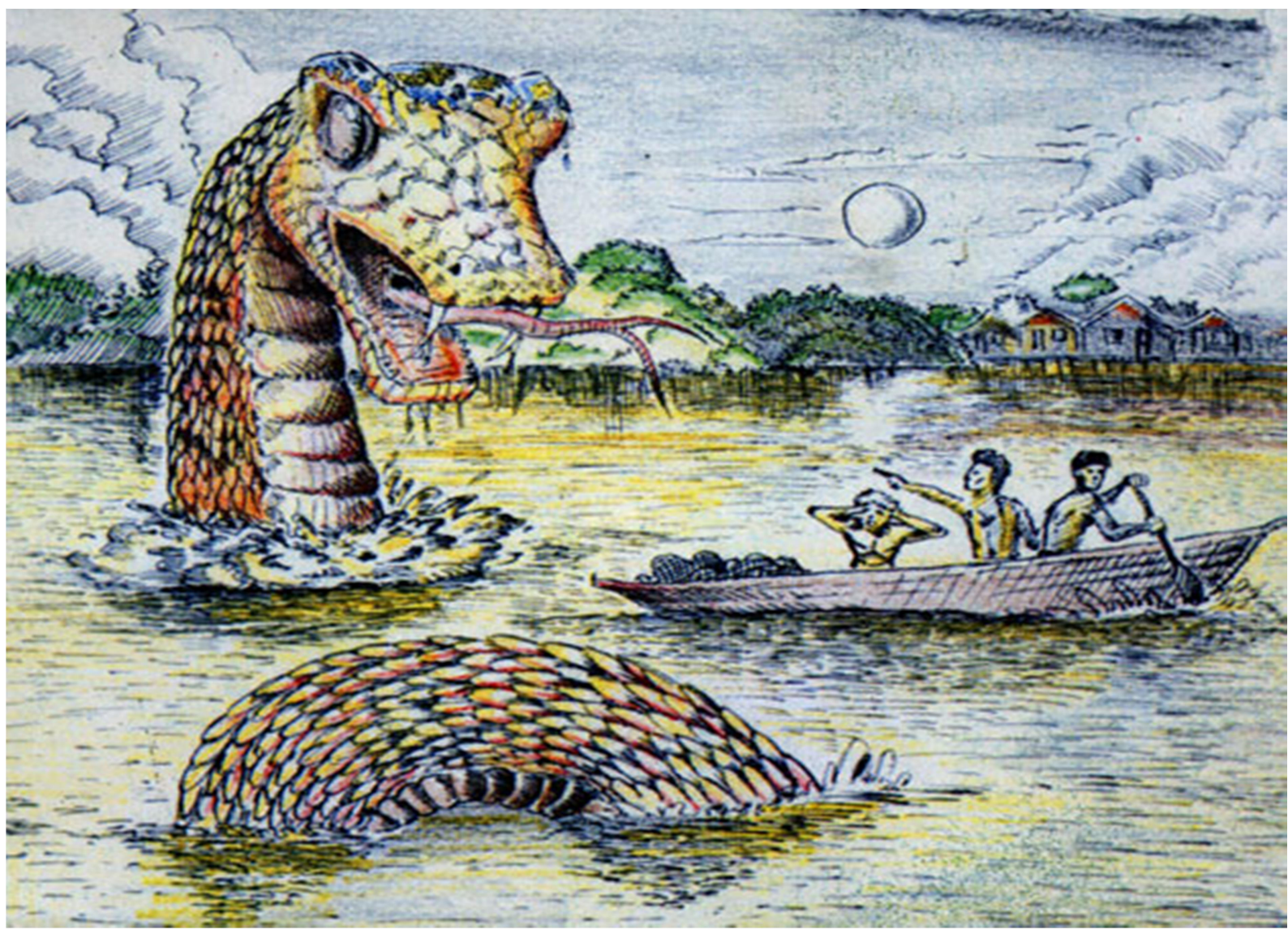

Fonte: O Portal de notícias de Tabatinga, no Amazonas

Entretanto, Canclini (2005) defende a tese de que o mundo globalizado não incorpora a concepção de homogeneidade total, pelo contrário, percebemos uma tentativa de "direito à diferença". Pois o mundo globalizado, segundo o autor, não unificou gostos e costumes. Pois estes aspectos estão em constante interação no cotidiano da urbanização.

Os movimentos sociais multiculturais enraizados no cotidiano dos espaços urbanos, mais especificamente, no ambiente ribeirinho mocajubense, devem ser pensados perante uma educação, na contemporaneidade, que valorize a dinâmica multicultural. Em contraposição, no que se refere a políticas tendenciosas, ocorrem movimentos de identidades indígenas com o objetivo de preservar o direito à terra de seus ancestrais.

Os PCNS procuram homogeneizar e garantir a equidade social escondendo as desigualdades. Vivemos em uma sociedade multicultural e nem todos têm as mesmas oportunidades de acesso à saúde, a educação e ao trabalho como princípio educativo.

Para promover uma educação multicultural crítica e emancipatória é necessário focar as atenções em alguns desafios no que tange: a desnaturalização e explicitação de preconceitos e discriminações, questionamento do mono culturalismo etnocêntrico, a relação 
entre igualdade e diferença, a construção das identidades socioculturais Via histórias ou narrativas, a promoção na prática educacional, de experiências de interação, o desenvolvimento de processos que possibilitem às pessoas serem sujeitos e cidadãos e a formação para a cidadania multicultural.

Os espaços, urbanos e ribeirinhos, mocajubenses concentram uma "polifonia caótica" que enraíza um multiculturalismo. Diante disso, viver nestes espaços multiculturais se torna um ato de 'consumismo simbólico'. O autor propõe políticas culturais para serem exercidas neste novo mundo globalizado, a saber: “a) pensar a heterogeneidade das cidades (adaptadas a cada zona, estrato econômico, grau de escolaridade, faixa etária) como algo democrático; b) levar em conta a variedade de necessidades da população já que a mesma cidade que massifica os comportamentos, oferece uma variada oferta de bens simbólicos; c) promover a cultura tradicional vinculada às novas condições de internacionalização."

Nesse sentido, adentramos ao âmbito metodológico deste estudo e destacamos que os discursos de cada professor de inglês foram cuidadosamente analisados e embasados teoricamente. $\mathrm{Na}$ apresentação dos dados, no que diz respeito a identificação dos docentes entrevistados, foram utilizados nomes fictícios baseados no folclore tradicional e nas lendas locais da cidade de Mocajuba. Assim a essência do tema tradução cultural será preservada em todos os pilares constitutivos deste trabalho, bem como a identidade dos professores que colaboraram com a pesquisa.

Pelo fato do trabalho em questão não se tratar de uma etnografia e sim de um estudo teórico, constituído também de narrativas orais de professores, optamos por substituir seus nomes por personagens e relacioná-los com a tradição de Mocajuba. Relacionando assim a temática do presente estudo com as descrições orais dos docentes.

Nesse sentido, na apresentação dos resultados foram utilizados alguns heterônimos oriundos do poema "Mocajuba 2" do professor Doutor Edir Augusto Dias Pereira, professor da UFPA, Campus Cametá. A escolha deste poema, que foi utilizado na descrição dos dados, se deu pelo fato da obra englobar uma série de informações que descrevem perfeitamente a cidade e cultura mocajubense. 
Figura 3: Poema Mocajuba 2

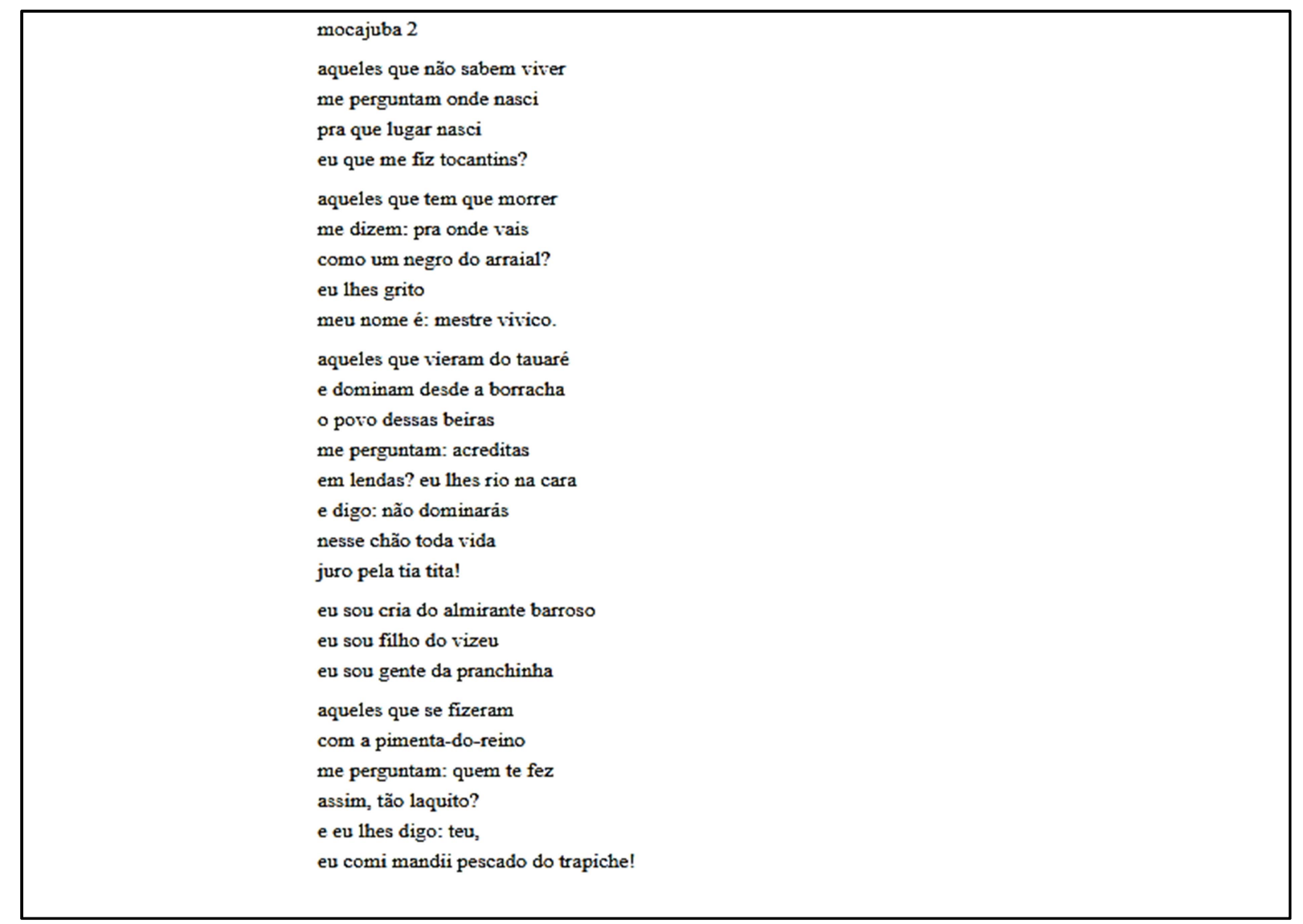

Fonte: Blog da Carmen Américo

Neste momento farei uma exposição dos dados da pesquisa, durante a apresentação utilizarei nomes que estão enraizados no poema acima, de forma que descreva a riqueza de detalhes que a pesquisa apresenta, sem mencionar diretamente os professores envolvidos no projeto.

Os docentes, que colaboraram com a pesquisa, são professores de um projeto social que possui parceria com a escola municipal de Ensino Fundamental Almirante Barroso, intitulado como Pedagogia da colaboração. O referido trabalho proporciona aulas, gratuitas, de língua estrangeira para jovens mocajubenses, com o intuito de melhorar a qualidade da educação na cidade.

Diante disso, em 2013 foram entrevistados dois professores que atuam no ensino de línguas no município de Mocajuba. Durante o período de realização das entrevistas, os docentes lecionavam as disciplinas de língua inglesa e espanhola na cidade. O presente projeto procurou focar sua análise na disciplina de inglês. 
Os professores relataram que durante as aulas promulgavam um ensino baseado no método gramática tradução, pois alegavam que os próprios parâmetros curriculares nacionais davam ênfase na habilidade da leitura como ferramenta primordial no ensino de um idioma. Entretanto um dos docentes entrevistados alegou que embora o foco estivesse na habilidade da leitura, não abandonava o ensino das outras habilidades, buscando desta maneira agregar em suas aulas atividades que abarcassem a comunicação.

Percebendo o interesse pelas outras habilidades, o docente desejava implementar um projeto social que buscasse complementar o ensino na região, de modo que auxiliasse no processo de ensino e aprendizagem de língua inglesa no município. Desta maneira, em 2014, com a análise dos dados investigativos foi desenvolvida uma roda de conversa com os docentes entrevistados. Na reunião foi decidido iniciar um projeto social focado no ensino de línguas estrangeiras, de maneira gratuita, visando a melhoria da qualidade da educação na cidade.

Assim, o projeto intitulado como cursinho popular auxiliou diversos jovens no município visando um ensino intercultural que buscasse agregar os aspectos linguísticos e culturais do idioma, promovendo assim uma educação multicultural.

Assim, consoante com o exposto apresento as narrativas orais dos professores da Escola Mocajubense. O professor Almirante Barroso, atua durante cinco anos neste projeto social. Durante suas aulas entrou em contato com mais de duzentos estudantes, durante os anos de 2013 a 2017. Nas palavras do docente o que mais motiva a ministrar aulas gratuitas para os jovens é ter ciência que "ao lecionar, eu como educador estarei semeando conhecimento e experiência de vida nos corações destes jovens".

O professor, então, relata que, durante as suas aulas, "as atividades de tradução são realizadas valendo do método gramática tradução com o objetivo de identificar cada componente linguístico e seu significado. Desta forma, os estudantes traduzem o texto do inglês para o português e descobrem assim o seu significado. Independente do conteúdo central do mesmo. Pois o foco é a estrutura gramatical e a preparação para testes de proficiência e exames vestibulares”.

Para Bhabha "a tradução, ou negociação é a habilidade de articular diferenças no espaço e no tempo, de ligar palavras e imagens em novas ordens simbólicas (BHABHA, 2011, p. 97). Assim segundo o autor é indispensável, durante uma atividade de tradução, a articulação das palavras com as imagens, símbolos e espaços presentes dentro do texto, pois estes pilares são essenciais no processo de contato com uma cultura diferente. 
Já o professor Vivido é docente colaborador do projeto pedagogia da colaboração há três anos. Neste projeto o docente procurou utilizar técnicas teatrais, durante as suas aulas, no intuito de despertar a sensibilidade dos estudantes perante os textos que são trabalhados ou diante das obras literárias abordadas.

Diante disso, o professor Vivico ressalta que "durante as aulas de tradução, busca interpretar o texto, juntamente com os estudantes valendo de todos os elementos presentes da cultura da língua inglesa. Pois considera ser essencial para o aprendizado do estudante". Desta forma o docente acentua que produz peças teatrais para proporcionar este contato com a outra cultura.

Segundo ele "é importante saber lidar e respeitar a diferença. Faço muitas atividades teatrais e procuro não apenas traduzir o que está escrito, mas também mostrar todos os lados da cultura para meus estudantes."

Bhabha ressalta que "o que é teoricamente inovador e politicamente crucial é a necessidade de passar além das narrativas de subjetividade originárias e iniciais e de focalizar aqueles momentos ou processos que são produzidos na articulação de diferenças culturais. (BHABHA, 2010, p. 20).

Os textos trabalhados em cada uma das aulas dos docentes abordaram temáticas como: xenofobia, que é a aversão ao estrangeiro, as festas populares, os pratos tradicionais, as músicas inglesas e a Sesta e o horário. Que aproximaram os discentes da cultura deste povo e puderam conhecer e respeitar as tradições e costumes enraizados na tradição que ultrapassam os anos.

\section{REFERÊNCIAS}

BHABHA, Homi K. O bazar global e o clube dos cavalheiros ingleses: textos seletos. Organização: Eduardo F. Coutinho. Tradução de Tereza Dias Carneiro. Rio de Janeiro: Rocco, 2011.

Representation and the Colonial Text: A Critical Exploration of Some forms of Mimeticism. IN: GLOVERSMITH, Frank. The theory of reading. Sussex: The Harvester Press, 1984, p. 93-122.

O Local da Cultura. Tradução de: Myriam Ávila; Eliana Lourenço de Lima Reis; Gláucia Renate Gonçalves. Belo Horizonte: Editora UFMG, 2010. 
CANCLINI, Néstor García. Consumidores e cidadãos: conflitos multiculturais da globalização. Rio de Janeiro: Editora UFRJ, 2005.

CANDAU, Vera Maria e MOREIRA, Antônio Flávio. Multiculturalismo - Diferenças Culturais e Práticas Pedagógicas. Petrópolis, RJ: Vozes, 2008.

CORAZZA, S. M.. Labirintos da pesquisa, diante dos ferrolhos. In: Marisa Vorraber Costa. (Org.). Caminhos Investigativos I. Novos olhares na pesquisa em educação. 3ed. Rio de Janeiro (RJ): Lamparina, 2007, v. 1, p. 103-127.

COSTA, Kleby Miranda. Vozes da Amazônia: o professor de espanhol como tradutor cultural na escola ribeirinha. Revista A palavrada, n. 13, v. 01, jan-jul, 2018.

COSTA, Kleby Miranda; LOUZADA, Elizângela Viana e SANTOS, Olaíza Quaresma dos. A constituição de identidades na amazônia: linguagens, saberes e culturas de povos ribeirinhos do baixo Tocantins/ PA. In: Cláudia Fuchs; Daniel Skrsypcsak; Jenerton Arlan Schütz., orgs. Debates e diálogos educacionais: reflexões contemporâneas. São Carlos: Pedro \& João Editores, 2019.

CLASTRES, Pierre. O arco e o cesto. In: CLASTRES, Pierre. A Sociedade contra o Estado. In Rio de Janeiro, 1978.

DERRIDA, Jaques. Torres de Babel. Tradução de Junior Barreto. Belo Horizonte: Editora UFMG, 2002.

ECO, Umberto. Quase a mesma coisa. Tradução de: Eliana Aguiar. Rio de Janeiro: Record, 2007.

FLEURI, Reinaldo Matias. Intercultura e educação. Revista Brasileira de Educação, Rio de Janeiro, v. 10, n. 23, maio/ago. 2003.

FREIRE, Paulo. Pedagogia da Autonomia. São Paulo: Paz e Terra, 1997.

FREIRE, Paulo. Pedagogia do Oprimido. São Paulo: Paz e Terra, 2009.

FOUCAULT, Michel. A ordem do discurso. Tradução de Laura Fraga de Almeida Sampaio. São Paulo: Edições Loyola, 2013.

GEERTZ, Clifford. A interpretação das culturas. - 1.ed., 13.reimpr. - Rio de Janeiro: :LTC, 2008.

HALL, Stuart. Identidade Cultural na pós-modernidade. 11. Ed. Rio de Janeiro: DP\&A, 2011.

LARROSA, B., Jorge. Notas sobre a experiência e o saber da experiência. Revista brasileira de educação, n 19, p. 20 - 30, Jane. / Fev/ Març. / Abr. 2000. 
NEVES, Maria Helena de Moura. A gramática Funcional. - São Paulo: Martins Fontes, 1997.

RICOEUR, Paul. Sobre a tradução. Tradução e prefácio Patrícia Lavelle. Belo Horizonte: Editora UFMG, 2011.

SILVA, Tomaz Tadeu da. (Org.). Identidade e diferença: a perspectiva dos Estudos Culturais. Petrópolis, RJ: Vozes, 2000.

SPINK, Mary Jane Paris. Pessoa, indivíduo e sujeito: notas sobre efeitos discursivos de opções conceituais. In: SPINK, MJP., FIGUEIREDO, P., and BRASILINO, J., orgs. Psicologia social e pessoalidade [online]. Rio de Janeiro: Centro Edelstein de Pesquisas Sociais; ABRAPSO, 2011, pp. 1-22.

TODOROV, Tzvetan. A Conquista da América: a questão do outro. Tradução: Beatriz Perrone Moisés. São Paulo, Martins Fontes, 1996. 